\title{
Testosterone and Aggression
}

\author{
John Archer \\ School of Psychology \\ University of Central Lancashire \\ Preston, UK \\ Justin M. Carré \\ Department of Psychology \\ Nipissing University \\ North Bay, Ontario, Canada
}




\section{Introduction: the mouse model}

It is well known that testosterone facilitates aggressive behavior in a wide range of birds and mammals. Bulls are viewed as dangerous whereas their castrated counterparts are not. Experimental studies have demonstrated, using the ablation-replacement method, that testosterone is responsible for territorial aggression in house mice (Beeman, 1947). Such laboratory studies were often used as "models" for human behavior, i.e., the controlled procedure provides a simplified version of the more complex human case.

It was with this "mouse model" in mind that studies began on the association between testosterone and aggression in humans, not of course involving castration and replacement, as with the experimental animals. Instead, correlational studies were undertaken to establish whether there was any association between blood plasma (and later salivary) levels of testosterone and aggressive behavior, typically measured by self-report questionnaires. The first of these found an association between testosterone production rate and measures of hostility in a small sample of young men (Persky, Smith, \& Basu, 1971). Since then, a range of other correlational studies have been reported, leading to the overall conclusion that there is a small association ( $r=0.08$ over 42 studies) between testosterone levels and measures of aggression (Archer, Graham-Kevan, \& Davies, 2005). The associations were strongest for young men and for offenders. Although there are fewer studies, there are also associations for women and for pre-pubertal boys (Archer, 2006).

In all of these studies, the evidence is for a link between testosterone and aggression: we cannot infer that there is, as in the case of other animals, a causal connection. There are three problems with using the data in this way. First, there is some evidence that being successful in aggressive competition can lead to an increase in testosterone levels, which could accumulate 
over time to produce higher levels in aggressive individuals. Second, the evidence from the few studies involving controlled trials of testosterone on measures of mood and aggression produced only a few isolated positive findings (Archer, 2006, Table 2). Third, a large-sample study of testosterone and aggression in boys going through puberty found no association between testosterone levels and aggression (Halpern, Udry, Campbell, \& Suchindran, 1994).

These reservations about a causal link have not stopped both psychologists and journalists believing that there is one. For example, one research group concluded: "The above information suggests that the rise in testosterone and thus aggressive behavior at puberty coincides with a time of intense competition for mates and/or status" (Book, Starzyk, \& Quinsey, 2005). Another research group concluded: "The male sex hormone testosterone contributes to high levels of violence in both sexes" (Stillman, Maner, \& Baumeister (2010). In this chapter, we argue that these statements are not wholly incorrect, but they do oversimplify a complex situation, which is better appreciated if we consider testosterone-aggression associations from an evolutionary perspective.

\section{An Evolutionary Framework for Testosterone and Aggression}

The evolutionary basis of the mouse model is usually implicit. Steroid hormones, including testosterone, are found throughout vertebrates, and are therefore likely to be of ancient origin (Baker, 1997). This ancient origin has led to a degree of consistency in the hormonebehavior relations throughout the vertebrates, in particular testosterone and related hormones (androgens) control the reproductive physiology and behavior of males in most vertebrate species. Since competition between males is necessary for successful breeding, the control of territorial and dominance-related aggression between males by testosterone provides a contextual link between success in aggressive encounters and in reproduction. Thus in a wide range of 
species, from all vertebrate groups (fish, amphibians, reptiles, birds and mammals), testosterone facilitates male aggression (Archer, 1988).

There are, however, many cases where this statement does not apply, and the neuroendocrine control of aggression is different in a number of the species that have been studied. It was against this background that the "Challenge Hypothesis" was first proposed to explain interspecific variations in the hormonal regulation of behavior in birds (Wingfield, 1984; Wingfield, Hegner, Dufty, \& Ball, 1990). It is based on the following evolutionary rationale: Continued high levels of testosterone are maladaptive, because they are associated with suppression of immune function and risky behavior. This hypothesis leads to two alternative adaptive solutions. The first is to incur these costs, which will be adaptive where the potential benefits of high testosterone are also great (i.e. when inter-male competition is high and success is necessary for mating opportunities). The second alternative is to maintain a lower level of testosterone that is sufficient for reproductive physiology and behavior, and to respond to challenges in reproductive contexts with a temporary increase in testosterone, which in turn supports inter-male competitive aggression in the short-term. This second alternative is typically, but not exclusively, found in species (such as most birds) where a considerable degree of paternal care is necessary for offspring survival.

The Challenge Hypothesis provides a more subtle and complex description of the association between testosterone and aggression than a model that assumes a straightforward causal relationship between testosterone and aggression. The Challenge Hypothesis does not rule out a causal link, but holds that it occurs in two circumstances: (1) in highly competitive, polygynous, species; and (2) in species with paternal care, during those phases of the life history when males are competing for females or for status and/or resources necessary for reproduction. 
Thus the restrictions of the original Challenge Hypothesis are that it applies primarily to monogamous and biparental species, and not to polygynous and non-parental species. In polygynous and non-parental species, levels of adult male testosterone are maintained at a high level as inter-male competition is high. Generally, there is support for the Challenge Hypothesis throughout the vertebrates, but not necessarily for the specific predictions that links it to biparental and monogamous species only (Hirschenhauser \& Olivera, 2006). Humans have been characterized as mildly polygynous or as monogamous. Studies of the relative variance in reproductive success of the two sexes, and the presence of sexually-selected attributes in humans (Archer, 2009), provide evidence for mild polygyny. Yet humans also have a considerable, but variable, degree of paternal care (Geary, 2000). This background, together with evidence supporting aspects of the Challenge Hypothesis in chimpanzees (Muller \& Wrangham, 2004), which is neither biparental nor monogamous, make it worthwhile examining whether the Challenge Hypothesis applies to humans.

\section{Assessing the Challenge Hypothesis in Humans}

The Challenge Hypothesis involves five predictions: (1) High testosterone levels will be associated with maladaptive attributes, both physical and behavioral; (2) There will be no increase in aggression as a function of the increased testosterone in males at puberty; (3) Adult males will respond to sexual and competitive situations with a transient increase in testosterone; (4) This testosterone surge will increase competitive aggression; and (5) Pair-bonding and paternal care will lead to a decrease in testosterone levels. Two additional predictions can be derived from the Challenge Hypothesis, although they are not part of the original hypothesis: (1) individual differences in testosterone levels will be associated with differences in the relative 
emphasis the person places on mating versus parental effort; and (2) many of the associations predicted for men will also be found in women.

In a review of studies involving testosterone and human behavior, evidence for most if not all of these predictions was found (Archer, 2006). Since then, a large number of additional relevant studies have been published. Here we concentrate on those that are concerned with testosterone and aggression, first that competitive situations will lead to increased testosterone, especially in the winners, and second that these relatively transient increases in testosterone will produce an increase in competitive and aggressive behavior.

\section{Does Competitive Behavior Increase Testosterone Levels?}

A central aspect of the Challenge Hypothesis is that there will be a testosterone increase as a consequence of competition in young men for women or for status. Although they were not aimed at testing this prediction, a number of previous studies have measured testosterone levels following inter-male competition in the form of sports activities, since these are likely to be equivalent to a challenge situation, particularly when they involve bodily contact (Archer 2006, p. 325). The findings were actually rather similar for physical and non-physical sports, and somewhat different to those for lab-based competitive situations (Archer, 2006).

A small increase in testosterone was found in anticipation of a sports competition $\left(d^{l}=\right.$ 0.30; 6 studies), although there was no appreciable increase in three other studies involving labbased tasks with arbitrary winners and losers. During the competition itself, testosterone levels increased in the studies involving sports, to a moderate extent $(d=0.37 ; 12$ studies $)$, but there was little or no increase for the lab-based tasks. In apparent contrast to these findings, there was

\footnotetext{
${ }^{1}$ These $d$ values refer to standardized differences between two groups or the same group at different times. In general terms, $d=0$ to 0.10 is a negligible difference, $d=0.11$ to 0.35 is a small difference, $d=0.36$ to 0.65 is a moderate, and $d=0.66$ to 1.00 is large. Thus the differences discussed here are in the small to moderate range. This classification is taken from Hyde (2005), and is based on the earlier values offered by Cohen (1988):"small" $d=$ 0.20 , "medium" $\mathrm{d}=0.50$, and "large" $\mathrm{d}=0.80$.
} 
little or no difference between winners and losers in sports competitions (there were substantial increases during the competition), whereas there were larger increases in winners than losers in the other tasks, which generally involved contrived winners and losers ( $d=0.38$; from 7 studies). One caution about these conclusions is that the studies typically involved small samples, and there was variability between studies. To seek to explain such variability, a number of studies have investigated possible mediators or moderators of the effects of winning on testosterone levels, in the form of personality variables. We consider the role of personality on the link between testosterone and aggression in a later section.

\section{Do Increased Testosterone Levels Increase Aggression?}

A crucial part of the original Challenge Hypothesis is that an increase in testosterone following competition will produce a transient increase in the willingness to respond to a challenge with aggression. In practice it is difficult to separate increased aggressiveness due to testosterone and that due to another cause and also occurring following a competitive encounter.

Studies of judo competitors found that increases in testosterone from before to after the bout were greater in competitors who looked angry and were more violent in their bouts, as judged by coaches (Suay et al., 1996). A follow-up study involving observations of participants' behavior found that initial testosterone levels were correlated with more attack, fighting and threat, as coded by two judo specialists (Salvador et al., 1999). If the initial testosterone levels represent an anticipatory rise in testosterone, as in other studies (Archer, 2006), this finding would fit the expectations of the Challenge Hypothesis. Alternatively, the pre-contest levels may reflect long-term circulating levels, and represent a stable individual difference in aggression that is associated with these circulating levels. 
More recent laboratory-based studies have examined the extent to which competitioninduced fluctuations in testosterone modulate subsequent competitive and aggressive behavior. In the first study (Mehta \& Josephs, 2006), men competed in dyads on a number-tracing task in which the outcome of the competition was rigged so that one person was assigned to experience a series of victories, whereas the other was assigned to experience a series of defeats. Saliva samples were collected before and after the competition. After the competition, participants were given the opportunity to pick the next task to be performed from two alternatives: either to compete against the same person on the same task; or to complete a questionnaire on entertainment preferences. A rise in testosterone predicted greater willingness to choose the competitive option, whereas a decrease in testosterone predicted a greater willingness to choose the non-competitive option. Notably, this effect was most robust among losers of a competitive interaction. Thus, losers whose testosterone increased during the competition were more likely than those whose testosterone decreased to choose the competitive option.

In another experiment, male participants performed the Point Subtraction Aggression Paradigm (PSAP) and provided saliva samples before and after the competition (Carré \& McCormick, 2008). The PSAP is a well-validated behavioral measure that assesses reactive aggression in a controlled laboratory setting (Cherek et al., 2006). After performing the PSAP, participants were given the opportunity to compete on a puzzle-solving task with the same person with whom they were paired on the PSAP (which was actually a computer program) or complete a questionnaire on music and food preferences. There was a positive correlation between aggressive behavior and changes in testosterone during the PSAP. Moreover, men showing a rise in testosterone during the PSAP were more likely to choose a subsequent 
competitive task than were men who showed a decrease in testosterone (Carré \& McCormick, 2008).

Although these findings indicate a positive correlation between competition-induced testosterone reactivity and aggressive behavior on the PSAP, the design of the study makes it difficult to draw strong conclusions regarding the direction of the effect. Although it is possible that a rise in testosterone during the PSAP promoted heightened aggressive behavior, it is equally possible that increased aggressive behavior on the PSAP promoted a robust increase in testosterone. To address this limitation, subsequent studies were designed to carefully assess aggressive behavior after a change in testosterone is detected.

In the first of these experiments, 99 participants each competed with a same-sex opponent on a number-tracing task. Saliva samples were collected before and after the competition. Next, participants performed the PSAP with the same opponent. Changes in testosterone in response to the number-tracing task were positively correlated with subsequent aggressive behavior for men, but not women (Carré, Putman, \& McCormick, 2009). In a subsequent study, with a larger sample $(n=237)$, participants played a video-game competition (volleyball or boxing) in which they were randomly assigned to experience a string of victories or defeats (Carré, Campbell, Lozaya, Goetz, \& Welker, 2013). Again, saliva samples were collected before and after the competition. Next, participants performed the PSAP against a same-sex opponent again (a computer program). Male (but not female) winners showed a larger increase in testosterone and were more aggressive than were losers. Notably, the association between winning and subsequent aggressive behavior was statistically mediated by changes in testosterone for men, but not for women. 
A third study investigated whether an intensive intervention program designed to curtail antisocial behavior reduced aggression through its modulation of neuroendocrine function (Carré, Iselin, Welker, Hariri, \& Dodge, 2014). At 6 years of age, at-risk children were randomly assigned to either a control group that received no specific program, or to an intervention group that received a comprehensive training program designed to increase their social competencies, including peer-mentoring, cognitive-behavioral training, and study skills. Participants from the intervention group showed a range of benefits compared to the control group (e.g., higher academic achievement, higher social competence, lower antisocial behavior, such as crime and drug-taking). However, the mechanisms through which the intervention reduced antisocial behavior were not clear. To investigate this, a subsample of men from the larger study were investigated at 26 years of age, to assess the extent to which the early intervention affected later aggressive behavior through different testosterone responses to social provocation (Carré et al., 2014). Participants provided saliva samples before, during, and after performing three $10 \mathrm{~min}$. blocks of the PSAP. The control and intervention groups did not differ in baseline testosterone concentrations or in aggressive behavior during the first block of the PSAP. However, the intervention group showed a decrease in testosterone after the first block of the PSAP and also a decrease in aggressive behavior in blocks 2 and 3 of the PSAP. In contrast, the control group showed an increase in testosterone after the first block of the PSAP and also an increase in aggressive behavior in blocks 2 and 3 of the PSAP. The decreased aggressive behavior in the intervention group was statistically mediated by dampened testosterone reactivity to the PSAP. This suggests that one (or more) components of the intervention program modulated the way the hypothalamic-pituitary-gonadal axis responded to social provocation. 
The findings reported in this section provide some support for the view that acute fluctuations in testosterone during competitive interactions may serve to fine-tune ongoing and/or future competitive and aggressive behavior. However, a major limitation of the evidence is that it is correlational. Thus, it is not possible to make strong causal claims concerning the role of testosterone in the modulation of human aggression. Research in animal models and recent pharmacological challenge probes designed for use in humans enable us to get one step closer toward understanding the neuroendocrine mechanisms underlying variability in aggression.

\section{Acute testosterone dynamics and aggression in animal models}

A number of animal studies have investigated the extent to which competition-induced changes in testosterone play a causal role in the modulation of future aggressive and competitive behaviour. In one study, a group of castrated male mice were randomly assigned to receive a single injection of testosterone or placebo after winning a competitive interaction (Trainor, Bird, $\&$ Marler (2004). The testosterone injection produced a very acute response, with testosterone concentrations rising rapidly, and then returning to baseline 45 minutes later. The next day, the mice engaged in another competitive interaction with a novel male. Those mice that received testosterone after winning a fight were more aggressive on the second (and third day) of testing. In a second study, the role of testosterone in mediating the 'winner' and 'loser' effects in male tilapia was examined (Oliveira Silva \& Canario, 2009). Winners of a first aggressive interaction were more likely to win a subsequent aggressive interaction ( $88 \%$ won a second fight), whereas losers were more likely to lose subsequent interactions ( $87 \%$ lost a second fight). However, winners treated with an anti-androgen drug, which prevented the normal increase in testosterone that occurs after winning a competition, were much less likely to win a subsequent aggressive interaction (44\% won a second fight). In contrast, losers treated with an androgen (11- 
ketotestosterone, the primary metabolite of $\mathrm{T}$ in fish) were not more likely to win a subsequent aggressive interaction ( $71 \%$ lost a second fight). These findings indicate that the 'winner effect' (but not the 'loser effect') depends critically on acute fluctuations in testosterone concentrations. Collectively, these results provide compelling support for the idea that competition-induced fluctuations in testosterone may enable organisms to adaptively fine-tune their social behavior according to their social context.

\section{Studies of Exogenously-Administered Testosterone}

Based on the Challenge Hypothesis, we would not necessarily expect long-term administration of testosterone to increase aggressiveness in men, and the null results in a number of studies is consistent with this expectation, as is the lack of evidence for a testosterone-induced increase in aggression at puberty (Archer, 2006). However, we might expect that testosterone administration would affect responses connected with aggressive responding in the short-term.

In a series of studies, an oral preparation of testosterone was administered to young female volunteers and their responses on a number of laboratory tasks were measured while their levels of testosterone were transiently increased to those typical of young men. Testosterone was found to alter a range of responses, some of which were directly related to aggression, and others to attributes associated with aggression. The first study found increases in the cardiac defense reflex to subliminally-presented angry faces (van Honk et al., 2001), the second study found increased eye gaze to angry faces (Terburg, Aarts \& van Honk, 2012), and the third study found decreased avoidance of angry faces when these were presented in a series of reaction-time tests involving approach or avoidance to happy, angry or neutral faces (Enter, Spinhoven, \& Roelofs, 2014). The findings from all three studies seem to indicate greater reactivity to briefly-presented angry faces, and that the effects are specific to anger rather than to other emotional expressions. 
Other studies have found that testosterone administration induces a decrease in cognitive empathy (Hermans, Putman, \& van Honk, 2006), and in the unconscious vigilant response to fearful faces (van Honk, Peper, \& Schutter, 2005), Both empathy and fear are attributes that are inversely related to aggression. Testosterone also produced lesser sensitivity to punishment (van Honk, Schutter, Hermans, Putman, Tuiten, \& Koppeschaar, 2004), which is associated with greater impulsiveness. Testosterone was also found to affect activity in brain regions associated with aggression: it led to increased amygdala and hypothalamic reactivity to angry faces (Hermans, Ramsay, \& van Honk, 2008; van Wingen et al., 2008), and decreased amygdalaorbitofrontal cortex connectivity (van Wingen et al., 2011).

These studies demonstrate that a wide range of measures that are directly or indirectly associated with aggression can be altered by short-term administration of testosterone. Nevertheless, there are two aspects of the methods used that may limit their applicability to situations where there is a transient rise in endogenous testosterone in men. First, the doses involved are clearly higher than those that young women would experience from endogenous testosterone. Second, women rather than men were involved in the studies (for the good reason that the physiological protocol for the hormone administration was only available for women).

To overcome these possible limitations, there are now novel pharmacological challenge paradigms that investigate the extent to which a single administration of testosterone modulates neural and behavioral processes in healthy young men (e.g., Eisenegger, von Eckardstein, Fehr, \& von Eckardstein, 2013; Goetz et al., 2014; Zak et al., 2009). One study examined the role of testosterone in modulating threat-related neural function (Goetz et al., 2014). Male participants were first given a gonadotropin-releasing hormone-antagonist (GnRH-ant), which temporarily suppressed testosterone concentrations and reduced variability in basal testosterone levels. After 
achieving testosterone suppression, participants were given a single dose of testosterone (100 mg, Androgel $®)$ to acutely elevate testosterone concentrations. Next, participants performed an emotion face-matching task during functional magnetic resonance imaging (fMRI). Within 90 minutes, testosterone rapidly increased amygdala, hypothalamic, and periaqueductal gray reactivity to angry, but not fearful or surprised faces. Notably, these same regions of the brain are rich in androgen receptors (Newman, 1999; Wood \& Newman, 1999), and also play a key role in modulating reactive aggression in animals (Blair, 2010). It should be noted that individuals at risk for engaging in reactive aggression also show heightened amygdala reactivity to angry facial expressions (Coccaro, McCloskey, Fitzgerald, \& Phan, 2007; Carré, Fisher, Manuck, \& Hariri, 2012).

The evidence presented in this section complements the studies of the link between competition-induced testosterone surges and aggression and competitive behavior, by indicating that exogenously-administered testosterone produces both behavioral and neurological changes which may predispose individuals toward aggressive behavior in the context of competitive and/or threat-related situations. Together these two lines of research seem to have produced the evidence needed to fill the gap in the Challenge Hypothesis (Archer, 2006). This does not mean that there is nothing left to investigate, since novel techniques provide the start of a series of further studies to cover other possible measures that might be influenced by testosterone (Goetz et al., 2014). In addition, there are a number of individual differences that are likely to complicate the existing findings. Some of these are discussed in the next two sections.

\section{The Influence of Personality}

A number of studies indicate that individual differences moderate the relationship between testosterone reactivity and aggressive behavior. An earlier study found that having a 
high level of a form of power motivation that involved using direct domination of others in faceto-face interactions was associated with larger post-competition increases in testosterone for both winners and losers of a contrived laboratory task, but especially for the winners (Schultheiss, Campbell, \& McClelland, 1999). The attribute identified in this study, seeking to dominate others in a direct and forceful way, is consistent with the Challenge Hypothesis as it would have been adaptive in direct competitive encounters between young men.

More recently, researchers have shown that a rise in testosterone among winners positively predicted subsequent aggression, but only among men scoring relatively high on trait dominance (Carré et al., 2009). Similarly, exogenous testosterone administration increases competitive motivation, but only among winners scoring relatively high in trait dominance (Mehta et al., in press). In two other studies (Norman, Moreau, Welker, \& Carré, J.M., 2015), a rise in testosterone during competition was associated with heightened aggressive behavior, but only among men (not women) scoring relatively low in trait anxiety (see Figure 1). These findings are notable in the light of animal research showing that trait anxiety modulates neuroendocrine function and aggression. Specifically, male rats selectively bred for low anxiety showed a heightened testosterone response to social threat and aggressive behavior relative to male rats bred for high anxiety (Veenema, Torner, Blume, Beiderbeck, \& Neumann, 2007).

\section{Dual Hormone Effects on Aggressive Behavior}

The research reviewed in this chapter suggests that competition-induced changes in testosterone may in part modulate ongoing and/or subsequent competitive and aggressive behavior. As indicated earlier, there is evidence for a weak association between trait-like testosterone (i.e., baseline levels) and aggressive behavior. A growing body of evidence suggests that this association may be more robust when one considers variability in cortisol 
concentrations. Cortisol is a steroid hormone secreted by the adrenal glands during periods of physical and psychological stress (Dickerson \& Kemeny, 2004). Research in adolescent males found that testosterone concentrations were positively correlated with physical aggression, but only among individuals with relatively low cortisol concentrations (Dabbs, Jurkovic, \& Frady, 1991; Popma et al., 2007). More recent research has found this pattern of findings for various measures that share conceptual and empirical overlap with aggression (e.g., risk-taking, dominance: see Mehta \& Prasad, 2015). However, other studies have not found this dual hormone effect (e.g., Mazur \& Booth, 2014), and others have found that testosterone is positively correlated with reactive aggression and psychopathic traits, but only among individuals with high cortisol concentrations (Denson et al., 2012; Welker et al., 2014). Clearly, more research will be required to determine if (and under what circumstances) testosterone and cortisol interact to predict variability in aggression and related constructs, and how this might be related to testosterone reactivity to competition.

\section{Conclusions}

In this chapter we have shown that the role of testosterone in modulation of aggression and related behavior is more complex than the simple cause and effect model originally derived from selective animal studies. A broader evolutionarily-based theory (the "Challenge Hypothesis") provided the basis for considering research that now dates back over 40 years, ranging from the initial correlational studies, to recent studies that involve sophisticated manipulation of testosterone levels, laboratory procedures rooted in experimental social psychology, and brain imaging. Taken together the emerging evidence shows that competitive behavior influences testosterone levels, which in turn influence aggressive behavior, in a complex way that is moderated by individual differences in personality. 


\section{References}

Archer, J. (1988). The behavioural biology of aggression. Cambridge, UK: Cambridge University Press.

Archer, J. (2006). Testosterone and human aggression: An evaluation of the challenge hypothesis. Neuroscience and Biobehavioral Reviews, 30, 319-335. http://dx.doi.org/10.1016/j.neubiorev.2004.12.007

Archer, J. (2009). Does sexual selection explain human sex differences in aggression? Behavioral and Brain Sciences, 32, 249-311. http://dx.doi.org/10.1017/S0140525X09990951

Archer, J., Graham-Kevan, N., \& Davies, M. (2005). Testosterone and aggression: A reanalysis of Book, Starzyk, and Quinsey’s (2001) study. Aggression and Violent Behavior, 10, 241-261. http://dx.doi.org/10.1016/j.avb.2004.01.001

Baker, M.E. (1997). Steroid receptor phylogyny and vertebrate origins. Molecular and Cellular Endocrinology, 135, 101-107. http://dx.doi.org/10.1016/S0303-7207(97)00207-4

Beeman, A.E. (1947). The effect of male hormone on aggressive behavior in male mice. Physiological Zoology, 20, 373-405.

Blair, R.J.R. (2010). Neuroimaging of psychopathy and antisocial behavior: A targeted review. Current Psychiatry Reports, 12, 76-82. http://dx.doi:10.1007/s11920-009-0086-x

Book, A.S., Starzyk, K.B., \& Quinsey, V.L. (2001). The relationship between testosterone and aggression: A meta-analysis. Aggression and Violent Behavior: A Review Journal, 6, 579-599. . http://dx.doi.org/10.1016/S1359-1789(00)00032-X

Carré, J.M., Campbell, J.A., Lozoya, E., Goetz, S.M.M., \& Welker, K.M. (2013). Changes in testosterone mediate the effect of winning on subsequent aggressive behaviour. 
Psychoneuroendocrinology, 38, 2034-2041.

http://dx.doi.org/10.1016/j.psyneuen.2013.03.008

Carré, J.M., Fisher, P.M., Manuck, S.B., \& Hariri, A.R. (2012). Interaction between trait anxiety and trait anger predict amygdale reactivity to angry facial expressions in men but not women. Social Cognitive and Affective Neuroscience, 7, 213-221.

http://dx.doi.org:10.1093/scan/nsq101

Carré, J.M., Iselin, A-M. R., Welker, K.M., Hariri, A.R., \& Dodge, K.A. (2014). Testosterone reactivity to provocation mediates the effect of early intervention on aggressive behavior. Psychological Science, 25, 1140-1146. http://dx.doi.org/10.1177/0956797614525642

Carré, J.M., \& McCormick, C.M. (2008). Aggressive behavior and change in salivary testosterone predict willingness to engage in a competitive task. Hormones and Behavior, 54, 403-409. http://dx.doi.org/10.1016/j.yhbeh.2008.04.008

Carré, J.M., Putman, S.K., \& McCormick, C.M. (2009). Testosterone responses to competition predict future aggressive behaviour at a cost to reward in men.

Psychoneuroendocrinology, 34, 561-570.

http://dx.doi.org/10.1016/j.psyneuen.2008.10.018

Cherek, D.R., Tcheremissine, O.V., \& Lane, S.D. (2006). Psychopharmacology of human aggression: Laboratory and clinical studies. In R.J. Nelson (Ed.), Biology of aggression (pp. 424-446). New York: Oxford University Press.

Coccaro, E. F., . McCloskey, M.S., Fitzgerald, D.A., \& Phan, K.L. (2007). Amydala and orbitofrontal reactivity to social threat in individuals with impulsive aggression. Biological Psychiatry, 62, 168-178. http://dx.doi.org/10.1016/j.biopsych.2006.08.024 
Cohen, J. (1988). Statistical power analysis for the behavioral sciences ( $2^{\text {nd }}$ ed.). New York: Academic Press.

Dabbs, J.M. Jr., Jurkovic, G.J., \& Frady, R.L. (1991). Salivary testosterone and cortisol among late adolescent male offenders. Journal of Abnormal Clinical Psychology, 19, 469-478. http://dx.doi.org/ 10.1007/BF00919089

Denson ,T.F., Mehta P.H., \& Ho Tan, D. (2013). Endogenous testosterone and cortisol jointly influence reactive aggression in women. Psychoneuroendocrinology, 38, 416-424. http://dx.doi.org/10.1016/j.psyneuen.2012.07.003

Dickerson, S.S., \& Kemeny, M.E. (2004). Acute stressors and cortisol responses: A theoretical integration and synthesis of laboratory research. Psychological Bulletin, 130, 355-391. http://dx.doi.org/10.1037/0033-2909.130.3.355

Eisenegger, C., von Eckardstein, A., Fehr, E., \& von Eckardstein, S. (2013). Pharmokinetics of testosterone and estradiol gel preparations in healthy young men. Psychoneuroendocrinology, 38, 171-178. http://dx.doi.org/10.1016/j.psyneuen.2012.05.018

Enter, D., Spinhoven, P., \& Roelofs, K. (2014). Alleviating social avoidance: Effects of single dose testosterone administration on approach-avoidance action. Hormones and Behavior, 65, 351-354. http://dx.doi.org/10.1016/j.ybeh.2014.02.001

Geary, D.C. (2000). Evolution and proximate expression of human paternal investment. Psychological Bulletin, 126, 55-77. http://dx.doi.org/10.1037/0033-2909.126.1.55

Goetz, S.M.M, Tang, L., Thomason, M.E., Diamond, M.P., Hariri, A.R., \& Carré, J.M., (2014). Testosterone rapidly increases neural reactivity to threat in healthy men: A novel two- 
step pharmacological challenge paradigm. Biological Psychiatry, 76, 324-331. http://dx.doi.org/10.1016/j.biopsych.2014.01.016

Halpern, C.T., Udry, J.R., Campbell, B., \& Suchindran, C. (1994). Relationships between aggression and pubertal increases in testosterone: A panel analysis of adolescent males. Social Biology, 40, 8-24.

Hermans, E.J., Putman, P., \& van Honk, J. (2006). Testosterone administration reduces empathic behavior: A facial mimicry study. Psychoneuroendocrinology, 31, 859-866. http://dx.doi.org/10.1016/j.psyneuen.2006.04.002

Hermans, E.J., Ramsay, N.F., \& van Honk, J. (2008). Exogenous testosterone enhances responsiveness to social threat in the neural circuitry of social aggression in humans. Biological Psychiatry, 63, 263-270. http://dx.doi.org/10.1016/j.biopsych.2007.05.013

Hirschenhauser, K., \& Oliveira, R.F. (2006). Social modulation of androgens in male vertebrates: Meta-analysis of the challenge hypothesis. Animal Behaviour, 71, 265-277. http://dx.doi.org/10.1016/j.anbehav.2005.04.014

Hyde, J.S. (2005). The gender similarities hypothesis. American Psychologist, 61, 581-592. http://dx.doi.org/10.1037/0003-066X.60.6.581

Mazur, A., \& Booth, A. (2014). Testosterone is related to deviance in male army veterans, but relationships are not moderated by cortisol. Biological Psychology, 96, 72-76. http://dx.doi.org/ 10.1016/j.biopsycho.2013.11.015

Mehta, P.H. \& Josephs, R.A. (2006). Testosterone change after losing predicts the decision to compete again. Hormones and Behavior, 50, 684-692. http://dx.doi.org/10.1016/j.yhbeh.2006.07.001 
Mehta, P.H., \& Prasad, S. (2015). The dual-hormone hypothesis: A brief review and future research agenda. Current Opinion in Behavioral Sciences, 3, 163-168. http://dx.doi.org/ 10.1016/j.cobeha.2015.04.008

Mehta, P.H., van Son, V., Welker, K.M., Prasad, S., Sanfey, A.G., Smidts, A., \& Roelofs, K. (in press). Exogenous testosterone in women enhances and inhibits competitive decisionmaking depending on victory-defeat experience and trait dominance. Psychoneuroendocrinology. http://dx.doi.org/10.1016/j.psyneuen.2015.07.004

Muller, M.N. \& Wrangham, R.W. (2004). Dominance, aggression and testosterone in wild chimpanzees: A test of the 'challenge' hypothesis. Animal Behaviour, 67, 113-123. http://dx.doi.org/10.1016/j.anbehav.2003.03.013

Newman S (1999). The medial extended amygdala in male reproductive behavior. A node in the mammalian social behavior network. Annals of the New York Academy of Sciences, 877, 242-257. http://dx.doi.org/ 10.1111/j.1749-6632.1999.tb09271.x

Norman, R.E., Moreau, B.J.P, Welker, K.M., \& Carré, J.M. (2015). Trait anxiety moderates the relationship between testosterone responses to competition and aggressive behavior. Adaptive Human Behavior and Physiology, 1, 312-324. http://dx.doi.org/ 10.1007/s40750-014-0016-y

Oliveira, R.F., Silva, A., \& Canario, A.V. (2009). Why do winners keep winning? Androgen mediation of winner but not loser effects in cichlid fish. Proceedings of the Royal Society of London: Biological Sciences, 276, 2249-2256 http://dx.doi.org/10.1098/rspb.2009.0132. 
Persky, H., Smith, K.D., \& Basu, G.K. (1971). Relation of psychological measures of aggression and hostility to testosterone production in man. Psychosomatic Medicine, 33, 265-277. http://dx.doi.org/10.1097/00006842-197105000-00007

Popma, A., Vermeiren, R., Geluk, C.A., Rinne, T., van den Brink, W., Knol, D.L.,... Doreleijers, T.A.H. (2007). Cortisol moderates the relationship between testosterone and aggression in delinquent male adolescents. Biological Psychiatry, 61, 405-411. http://dx.doi.org/10.1016/j.biopsych.2006.06.006

Salvador, A., Suay, F., Martinez-Sanchis, S., Simon, V.M., \& Brain, P.F. (1999). Correlating testosterone and fighting in male participants in judo contests. Physiology and Behavior, 68, 205-209. http://dx.doi.org/10.1016/S0031-9384(99)00168-7

Schultheiss, O.C., Campbell, K.L., \& McClelland, D.C. (1999). Implicit power motivation moderates men's testosterone response to imagined and real dominance success. Hormones and Behavior, 36, 234-241. http://dx.doi.org/10.1006/hbeh.1999.1542

Stillman, T.F., Maner, J.K., \& Baumeister, R.F. (2010). A thin slice of violence: distinguishing violent from nonviolent sex offenders at a glance. Evolution and Human Behavior, 31, 298-303. http://dx.doi.org/10.1016/j.evolhumbehav.2009.12.001

Stanton, S.J., Wirth, M.M., Waugh, C.E., \& Schultheiss, O.C. (2009). Endogenous testosterone levels are associated with amygdale and ventromedial prefrontal cortex responses to anger faces in men but not women. Biological Psychology, 81, 118-122. http://dx.doi.org/10.1016/j.biopsycho.2009.03.004

Suay, F., Salvador, A., González-Bono, E., Sanchis, C., Simon, V.M., \& Montoro, J.B. (1996). Testosterona y evaluacion de la conducta adresiva en jovenes judokas. Revista de Psicologia del Deporte [Journal of Sport Psychology], 9/10, 79-91. 
Terburg, D., Aarts, H., \& van Honk, J. (2012). Testosterone affects gaze aversion from angry faces outside of conscious awareness. Psychological Science, 23, 459-463. http://dx.doi.org/10.1177/0956797611433336

Trainor, B.C., Bird, I.M., \& Marler, C.A. (2004). Opposing hormonal mechanisms of aggression revealed through short-lived testosterone manipulations and multiple winning experiences. Hormones and Behavior, 45, 115-121. http://dx.doi.org/10.1016/j.yhbeh.2003.09.006

van Honk, J., Peper, J.S., \& Schutter, D.J.L.G. (2005). Testosterone reduces unconscious fear but not consciously experienced anxiety: Implications for the disorders of fear and anxiety. Biological Psychiatry, 58, 218-225. http://dx.doi.org/10. 1016/j.biopsych.2005.04.003

van Honk, J., Schutter, D.J.L.G., Hermans, E.J., Putman, P., \& Koppeschaar, H. (2004). Testosterone shifts the balance between sensitivity for punishment and reward in healthy young women. Psychoneuroendocrinology, 29, 937-943. http://dx.doi.org/10.1016/j.psyneuren.2003.08.007

van Honk, J., Tuiten, A., Hermans, E.J., Putman, P., Koppeschaar, H. Thijssen, J.,...van Dooren, L. (2001). A single administration of testosterone induces cardiac acceleration response to angry faces in healthy young women. Behavioral Neuroscience, 115, 238-242. http://dx.doi.org/10.1037/0735-7044.115.1.238

van Wingen, G.A., Zylicz, A., Pieters, S., Mattern, C., Verkes, R.J., Buitelaar, J.K., (2008). Testosterone increases amygdala reactivity in middle-aged women to a young adulthood level. Neuropsychopharmacology, 34, 539-547.. http://dx.doi.org/10.1038/sj.npp.2008.2 
van Wingen, G.A., Ossewaarde, L., Backstrom, T., Hermans, E.J., \&Fernandez, G. (2011). Gonadal hormone regulation of the emotion circuitry in humans. Neuroscience, 191, 3845. http://dx.doi.org/10.1016/j.neuroscience.2011.04.042

Veenema, A.H., Torner, L., Blume, A., Beiderbeck, D.L., \& Neumann, I.D. (2007). Low inborn anxiety correlates with high intermale aggression: link to ACTH response and neuronal activation of the hypothalamic paraventricular nucleus. Hormones and Behavior, 51, 1119. http://dx.doi.org/ 10.1016/j.yhbeh.2006.07.004

Welker, K.M., Lozoya, E., Campbell, J.A., Neumann, C.S., \& Carré, J.M. (2014). Testosterone cortisol, and psychopathic traits in men and women. Hormones and Behavior, 129, 230236. http://dx.doi.org/ 0.1016/j.physbeh.2014.02.057

Wingfield, J.C. (1984). Androgens and mating systems: Testosterone- induced polygyny in a normally monogamous bird. The Auk, 4, 665-671. http://dx.doi.org/10.2307/4086893

Wingfield, J.C., Hegner, R.E., Dufty Jr., A.M., \& Ball, G.F. (1990). The 'challenge hypothesis': theoretical implications for patterns of testosterone secretion, mating systems, and breeding strategies. American Naturalist, 136, 829-846. http://dx.doi.org/10.1086/285134

Wood, R., \& Newman, S.W. (1999). Androgen receptor immunoreactivity in the male and female Syrian hamster brain. Journal of Neurobiology, 39, 359-370. http://dx.doi.org/10.1002/(SICI)1097-4695(19990605)39:3<359::AID-NEU3>3.0.CO;2W

Zak, P.J., Kurzban, R., Ahmadi, S., Swerdloff, R.S., Park, J., Efremidze, L., ...Matzner, W. (2009). Testosterone administration decreases generosity in the Ultimatum Game. PLoS ONE 4: e8330. http://dx.doi:10.1371/journal.pone.0008330 
Figure 1. Trait anxiety moderates the relationship between competition-induced testosterone reactivity and aggressive behavior in men. Note: This figure is re-drawn based on the findings of Norman et al. (2015). Simple slopes are depicting at low vs. high anxiety scores (i.e., anxiety scores at $-1 /+1$ SD from the mean). Results indicate a strong positive correlation between testosterone reactivity during competition and subsequent aggression among men scoring low in trait anxiety $(B=.29, S E=.12, p=.01)$, but not high in trait anxiety $(B=-.06, S E=.12, p=.62)$ 